\title{
Anabases
}

ANABASES Traditions et réceptions de l'Antiquité

$15 \mid 2012$

Varia

\section{Luciano CANFORA et al., Fotografia e falsificazione}

\section{Germaine Aujac}

\section{OpenEdition}

\section{Journals}

Édition électronique

URL : http://journals.openedition.org/anabases/3829

DOI : 10.4000/anabases.3829

ISSN : 2256-9421

\section{Éditeur}

E.R.A.S.M.E.

\section{Édition imprimée}

Date de publication : 1 avril 2012

Pagination : 265

ISSN : 1774-4296

\section{Référence électronique}

Germaine Aujac, "Luciano canfora et al., Fotografia e falsificazione », Anabases [En ligne], 15 | 2012, mis en ligne le 01 avril 2012, consulté le 22 septembre 2020. URL : http://journals.openedition.org/ anabases/3829; DOI : https://doi.org/10.4000/anabases.3829

Ce document a été généré automatiquement le 22 septembre 2020.

(c) Anabases 


\title{
Luciano CANFORA et al., Fotografia e falsificazione
}

\author{
Germaine Aujac
}

\section{RÉFÉRENCE}

Luciano CANFORA et al., Fotografia e falsificazione, Scuola Superiore di Studi Storici, San

Marino, AIEP, 2011, 90 p. +51 pl.

10 euros / ISBN 978-88-6086-069-9.

1 Ce mince volume représente les actes d'un colloque qui s'est tenu au département des études historiques de l'université de Saint-Marin, les 5 et 6 novembre 2010. Les huit participants se proposaient d'analyser et de décrire si possible le contenu de cet amas, connu sous le nom de Konvolut, d'où étaient extraits les fragments de papyrus attribués par certains au géographe Artémidore.

2 Luciano Canfora («Perché questo convegno», p. 7-14) précise les buts poursuivis : se faire une idée claire du conglomérat d'origine, connu jusqu'à présent par une seule photo (ou plutôt un photomontage) montrée à l'occasion du congrès de Berlin en mars 2008. L'original de cette photo était beaucoup plus petit; quant au négatif, il se trouve chez le vendeur de ce Konvolut, le Dr Serop Simonian de Hambourg, qui n'a pas répondu à l'invitation de participer au colloque de Saint-Marin.

3 Giovanni Bottiroli (« La Fotografia del Konvolut del papiro di Artemidoro di Efeso. Nuove risultanze emerse dall'analysi delle scritture », p. 15-21), en conclusion de ses analyses d'écritures, émet de sérieux doutes sur l'authenticité de la photographie du Konvolut, ce qui justifie les soupçons de manipulation.

4 Claudio De Simoni («Il negativo fantasma », p. 23-29) s'est livré à une analyse précise de la photo dont l'original se trouve à Milan; il a réclamé en vain au vendeur Simonian l'envoi du négatif correspondant. 
5 Salvatore Granata (« La fotografia del Konvolut del papiro di Artemidoro. Analisi digitale della Stampa fotografica riproducente il Konvolut del papiro di Artemidoro prima del restauro ", p. 31-46) rappelle l'histoire de ce Konvolut de papier mâché qui, d'Égypte, est parvenu en Allemagne en 1971 ; un rouleau fut acheté par la Fondation pour l'art de Turin en 2004 et confié au laboratoire de papyrologie de l'université de Milan pour y être restauré. Des analyses précises, abondamment illustrées, fondées sur l'histoire de la photographie, permettent de dater les divers clichés du Konvolut.

6 Dans l'article suivant ("The photograph of the Artemidorus papyrus Konvolut. Comparative digital analysis", p.47-57), Salvatore Granata reprend les mêmes opérations, effectuées à la demande de Silio Bozzi, de la police scientifique d'Ancone.

7 Le même Silio Bozzi avait chargé le Centre d'études photographiques de Milan d'examiner des reproductions du Konvolut. Sergio Namias ("Datazione di un negativo », p. 59-68) conclut prudemment qu'on ne peut leur donner une date précise.

8 Alberto Cottignoli ("Il papiro di Artemidoro : un clamoroso falso », p. 69-76) s'intéresse aux dessins qui figurent sur ce papyrus ; il y voit l'œuvre d'un faussaire.

9 Silio Bozzi («Konvolut, ovvero elogio filosofico di un falso», p. 77-90) réfute les affirmations du professeur Galazzi et du Dr Bauman qui soutiennent l'authenticité du papyrus. Il les accuse de faire l'éloge explicite et scandaleux d'un faux. La polémique n'est donc pas près de s'éteindre.

\section{AUTEURS}

\section{GERMAINE AUJAC}

Université de Toulouse (UTM)

aujac.germaine@wanadoo.fr 